\title{
Effects of Rhenium(I)-diselenoether and of its Diselenide Ligand on the Production of Cathepsins B and S by MDA-MB231 Breast Malignant Cells
}

\author{
PHILIPPE COLLERY ${ }^{1}$, VIJAYKUMAR VEENA ${ }^{2}$, DIDIER DESMAËLE ${ }^{3}$, \\ ADHIKESAVAN HARIKRISHNAN ${ }^{4}$ and BASAVEGOWDA LAKSHMI ${ }^{5}$ \\ ${ }^{1}$ Society for the Coordination of Therapeutic Research, Algajola, France; \\ ${ }^{2}$ Department of Biotechnology, School of Applied Sciences, REVA University, Bangalore, India; \\ ${ }^{3}$ Galien Institute, Paris-Saclay University, Châtenay-Malabry, France; \\ ${ }^{4}$ Department of Chemistry, School of Arts and Science, \\ Vinayaka Mission Research Foundation-AV Campus, Chennai, India; \\ ${ }^{5}$ Department of Chemistry, School of Applied Sciences, REVA University, Bangalore, India
}

\begin{abstract}
Background/Aim: Rhenium(I)-diselenoether (RediSe) is a drug under development for the treatment of metastatic cancers, with selective inhibitory effects on MDAMB231 cancer cells compared to normal HEK-293 cells, and with greater effects than its diselenide (di-Se) ligand. Rhenium (Re) compounds inhibit cathepsins, which are important proteolytic enzymes in cancer. This study investigated the effects of Re-diSe and di-Se on the production of cathepsins B and $S$ in MDA-MB231 malignant and HEK-293 normal cells and their inhibitory effects following treatment with different doses for 72 h. Materials and Methods: Elisa tests were used to assay the amount of cathepsins $B$ and $S$ in the medium of cultures. Results: Re-diSe, but not diSe affected the viability of malignant cells and the expression of cathepsins B and S. Conclusion: To the best of our knowledge, this is the first demonstration that Re-diSe may decrease the production of cathepsins $B$ and $S$ in cancer cells at doses as low as $10 \mu \mathrm{M}$.
\end{abstract}

Cathepsins have a role in cancer development (1) and in tumor-associated immune cell functions (2). Since 2006, it is known that rhenium $(\mathrm{Re})$ compounds inhibit the activity of cathepsin B (3). This was confirmed 2 years later by

This article is freely accessible online.

Correspondence to: Dr. Philippe Collery, Society for the Coordination of Therapeutic Research, 20220 Algajola, France. Tel: +33 640419253, e-mail: philippe.collery@gmail.com; Dr. Vijaykumar Veena, Department of Biotechnology, School of Applied Sciences, REVA University, Bangalore 560064, India. Tel: +91 08066226622, email: btveenavijaykumar@gmail.com; veena.v@reva.edu.in

Key Words: Cathepsins, cysteine proteases, rhenium, selenium.
Fricker et al. (4). Among cathepsins, cysteine proteases are targets of metal-based drugs (5).

Rhenium(I)-diselenoether (Re-diSe) is a drug under preclinical development for the treatment of metastatic triplenegative breast cancer, with selective inhibitory effects on MDA-MB231 cancer cells compared to normal HEK-293 cells. Re-diSe displayed greater effects than its free diselenide (diSe) ligand, emphasizing the role of the $\operatorname{Re}$ metal $(6,7)$. The selective decreased expression of ROS, TNF- $\alpha$, VEGF, TGF$\beta$ in MDA-MB231 cancers cells in comparison with normal HEK-293 cells after treatment with Re-diSe has also been observed, but no study has yet been performed on cathepsins. Therefore, this study aimed to study the expression of cathepsins B and S in Re-diSe- and diSe-treated MDA-MB231 cancer cells and normal HEK-293 cells and to correlate the results obtained with the inhibitory effects of the drugs.

\section{Materials and Methods}

Synthesis of the drugs. The procedure of synthesis of the diSe ligand and the Re-diSe complex have been previously reported $(6,8)$.

Cell lines and reagents. Cell lines were purchased from the National Centre for Cell Science (NCCS), Pune, India and maintained in a $\mathrm{CO}_{2}$ incubator as per the standard protocol. Dimethyl sulfoxide (DMSO), Dulbecco's modified eagle medium (DMEM), fetal bovine serum (FBS), Rosewell park memorial institute (RPMI), penicillin, streptomycin, amphotericin B, 3-(4, 5-dimethylthiazol-2yl)-2,5-diphenyl tetrazolium bromide (MTT), and ethidium bromide (EB) were purchased from Sigma Aldrich (St. Louis, MO, USA). ELISA kits for the biomarkers were purchased from ELabscience (Houston, TX, USA).

Assays of the inhibitory effects. The inhibitory effects were studied by the (3-(4,5-dimethylthiazol-2-yl)-2,5-diphenyltetrazolium bromide) 


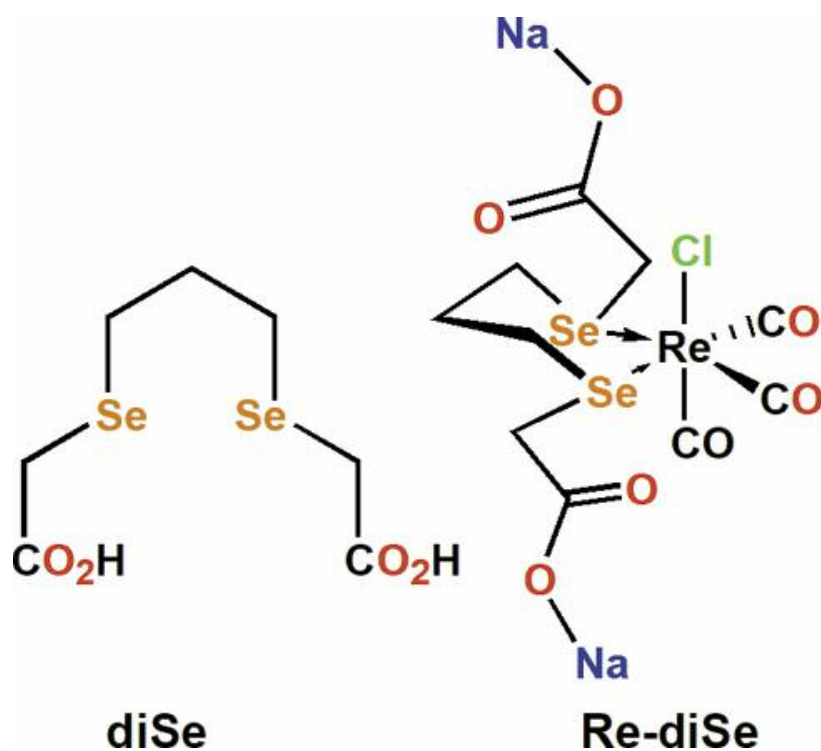

Figure 1. Structure of the rhenium complex Re-diSe and its 3,7-diselenanonanedioic acid ligand (diSe).

tetrazolium reduction assay (MTT test). They were assayed in hormone-independent MDA-MB231 breast cancer cells and in the normal human embryonic kidney cell line (HEK-293).

The inhibitory effects were assayed after exposure of cells to the drug for $72 \mathrm{~h}$ at doses of $5,10,25,50$, and $100 \mu \mathrm{M}$. We compared the effects of the Re-diSe compound versus its di-Se ligand. The drug concentration leading to $50 \%$ inhibition of the proliferation of cells $\left(\mathrm{IC}_{50}\right)$ was defined.

Assays of cathepsins. Cathepsins B and S were assayed by ELISA tests in the culture medium, reflecting their release by the cells, but not directly in the cells, where the changes are far too rapid to be detected by these methods.

Statistical analysis. Results are expressed as mean \pm SD of triplicate experiments. The statistical analysis was performed using the SPSS software (IBM, Chicago, IL, USA). The comparison of the efficacy of the Re-diSe drug to inhibit cancer and normal cell lines was analyzed using the Mann-Whitney $U$-tests. Results were considered statistically significant at $p<0.05$.

\section{Results}

Structure of Re-diSe. The rhenium(I)-diselenoether complex depicted in Figure 1 features a central $\left.f a c-\left[\operatorname{Re}(\mathrm{CO})_{3}\right)\right]$ core coordinated by two Se atoms bearing to acetic acid appendages. Conversion of the two carboxylic acid functions into water-soluble disodium salt markedly facilitates its application in biological systems. This complex was obtained by simple ligand exchange reaction of pentacarbonylchlororhenium (I) with 3,7-diselena nonanedioic acid (diSe, Figure 1).
Inhibitory effects. The $\mathrm{IC}_{50}$ of Re-diSe in malignant cells was $50 \mu \mathrm{M}$ and was not reached with diSe. The selectivity of Re-diSe for malignant cells was confirmed by the less than $10 \%$ inhibitory effect of this dose $(50 \mu \mathrm{M})$ in normal HEK-293 cells. A significant decrease in the cell proliferation of normal cells was only observed with the 100 $\mu \mathrm{M}$ dose of Re-diSe. The effect of Re-diSe was dosedependent, with a significant decrease in the proliferation of malignant cells from $10 \mu \mathrm{M}$, with significantly increased effects at higher doses. Treatment with $50 \mu \mathrm{M}$ di-Se ligand inhibited proliferation of malignant cells by less than $10 \%$, as observed in normal cells. The diSe compound had no significant effect on cell viability following treatment for 72 $\mathrm{h}$, even at the dose of $100 \mu \mathrm{M}$. The results are shown in Figure 2.

\section{Expression of cathepsins}

Cathepsin $S$. The levels of cathepsin $\mathrm{S}$ were significantly higher in the medium of malignant MDA-MB231 cells than in the medium of normal HEK-293 cells after $72 \mathrm{~h}$ of culture in non-treated cells.

A significant decrease in cathepsin $\mathrm{S}$ was observed following treatment of malignant cells with $10 \mu \mathrm{M}$ of RediSe and the effects were dose-dependent (Figure 3). The decrease in cathepsin $\mathrm{S}$ was only significant in normal cells treated with $50 \mu \mathrm{M}$ Re-diSe, which was the $\mathrm{IC}_{50}$ dose for malignant cells. At the dose of $10 \mu \mathrm{M}$, the levels of cathepsin $\mathrm{S}$ decreased in the medium of malignant cells from $501 \pm 23$ $\mathrm{pg} / \mathrm{ml}$ (non-treated cells) to $457 \pm 2 \mathrm{pg} / \mathrm{ml}(p<0.05)$ and from $325 \pm 34 \mathrm{pg} / \mathrm{ml}$ (non-treated cells) to $316 \pm 30 \mathrm{pg} / \mathrm{ml}$ in the medium of normal cells (N.S). The diSe drug had no significant effect on the levels of cathepsin S.

Cathepsin B. The levels of cathepsin B in non-treated cells were significantly higher in the medium of malignant MDAMB231 cells than in the medium of normal HEK-293 cells after $72 \mathrm{~h}$ of culture.

A significant decrease in cathepsin B was observed at the dose of $10 \mu \mathrm{M} / \mathrm{l}$ of Re-diSe both in normal and malignant cells compared to non-treated cells (Figure 4). The effects were dose-dependent. At the dose of $10 \mu \mathrm{M} / 1 \mathrm{Re}$-diSe, the levels of cathepsin B decreased from $5619 \pm 68 \mathrm{pg} / \mathrm{ml}$ to $5012 \pm 80 \mathrm{pg} / \mathrm{ml}(p<0.05)$ in the medium of malignant cells and from $4538 \pm 28 \mathrm{pg} / \mathrm{ml}$ to $4231 \pm 38 \mathrm{pg} / \mathrm{ml}$ in the medium of normal cells $(p<0.05)$. The diSe had no significant effect on the levels of cathepsin B.

\section{Discussion}

Cathepsins are classified according to the amino acids of their active sites in three classes: aspartic, cysteine, or serine proteases (9). The nucleophile is provided by a sulfhydryl group of cysteine in cysteine cathepsins. 

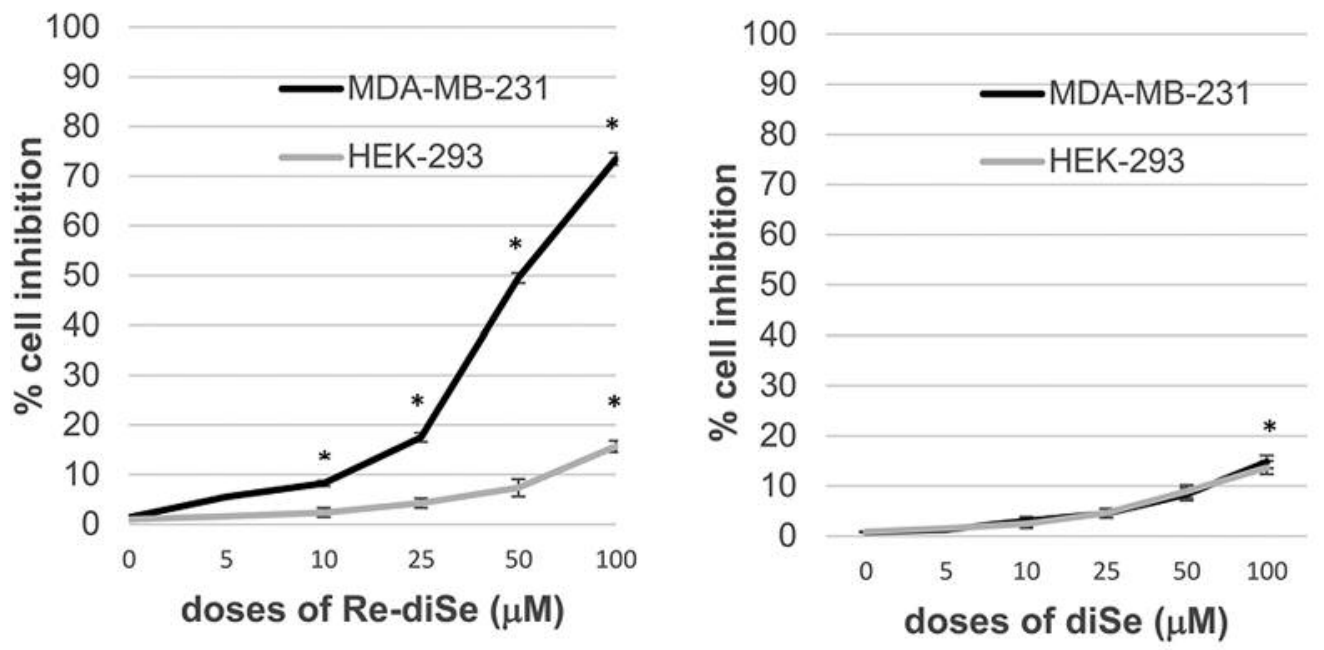

Figure 2. Dose effects of Re-diSe and diSe on the proliferation of MDA MB-231 and HEK-293 cells ( ${ }^{*} p<0.05$ versus non-treated cells).
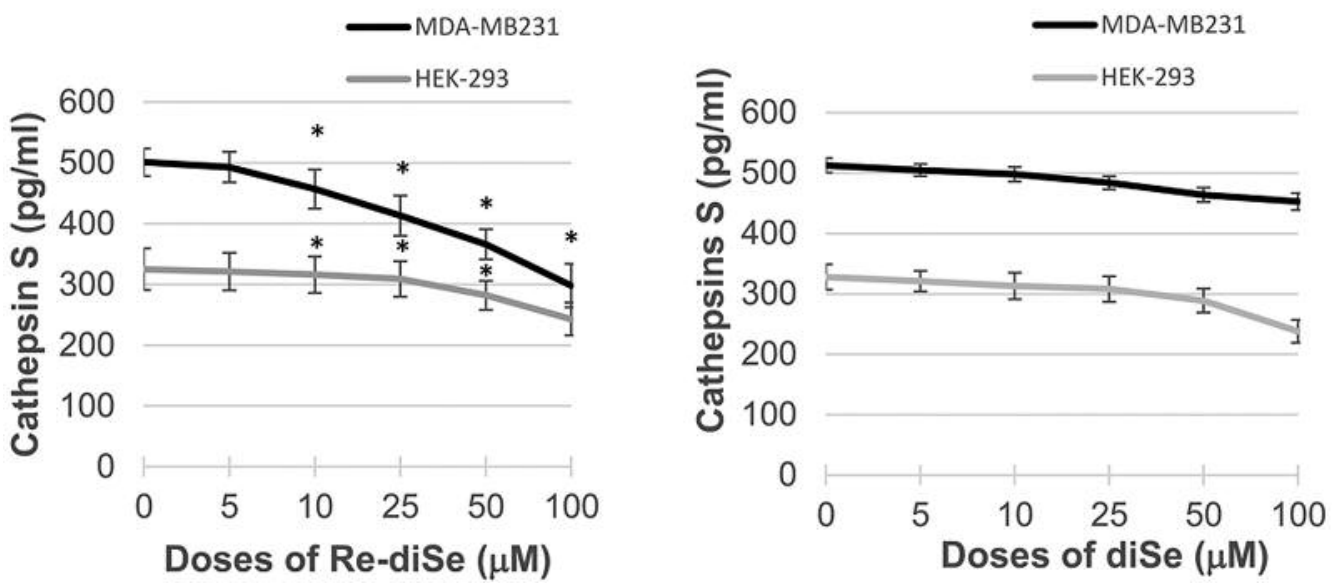

Figure 3. Dose-effects of Re-diSe and diSe on the production of cathepsin S by MDA-MB231 cancer cells and HEK293 normal cells (*p<0.05 versus non-treated cells).

There are two distinct subfamilies of cysteine proteases, cathepsin-L-like (cathepsins L, V, K, S, W, F, and H) and cathepsin-B-like proteases, which can be distinguished by the structure of the prodomain and the mature domain, with two conserved motifs (ERFNIN and GNFD) in the prodomain of the cathepsin L subfamily, while the ERFNIN motif is lacking in cathepsins $\mathrm{B}, \mathrm{C}, \mathrm{O}$, and $\mathrm{X}(10)$. Cathepsins B and L are papain-like enzymes. Their zymogen inactive forms have to be activated to obtain the enzymatic function. Comparisons between procathepsins $\mathrm{B}$ and $\mathrm{L}$ have been well described by Verma et al. (10). Cathepsin S was chosen in our study as a member of the cathepsin L subfamily. Cathepsin B was chosen as a member of the other subfamily, with a characteristic feature due to an "occluding loop", which provides carboxydipeptidase activity.

We demonstrated in this study that Re-diSe, but not diSe, selectively inhibited the proliferation of breast cancer cells that over-express cathepsins B and S, compared to normal cells.

We also observed a dose-dependent decrease in both cathepsin $\mathrm{B}$ and $\mathrm{S}$ in malignant cells, from the low dose of $10 \mu \mathrm{M}$ Re-diSe, whereas the $\mathrm{IC}_{50}$ was $50 \mu \mathrm{M}$. There is an increased expression of cathepsins in cancers (11) and a higher expression of cathepsins in MDA-MB-231 cancer cells versus normal HEK-293 cells was found in this study. 

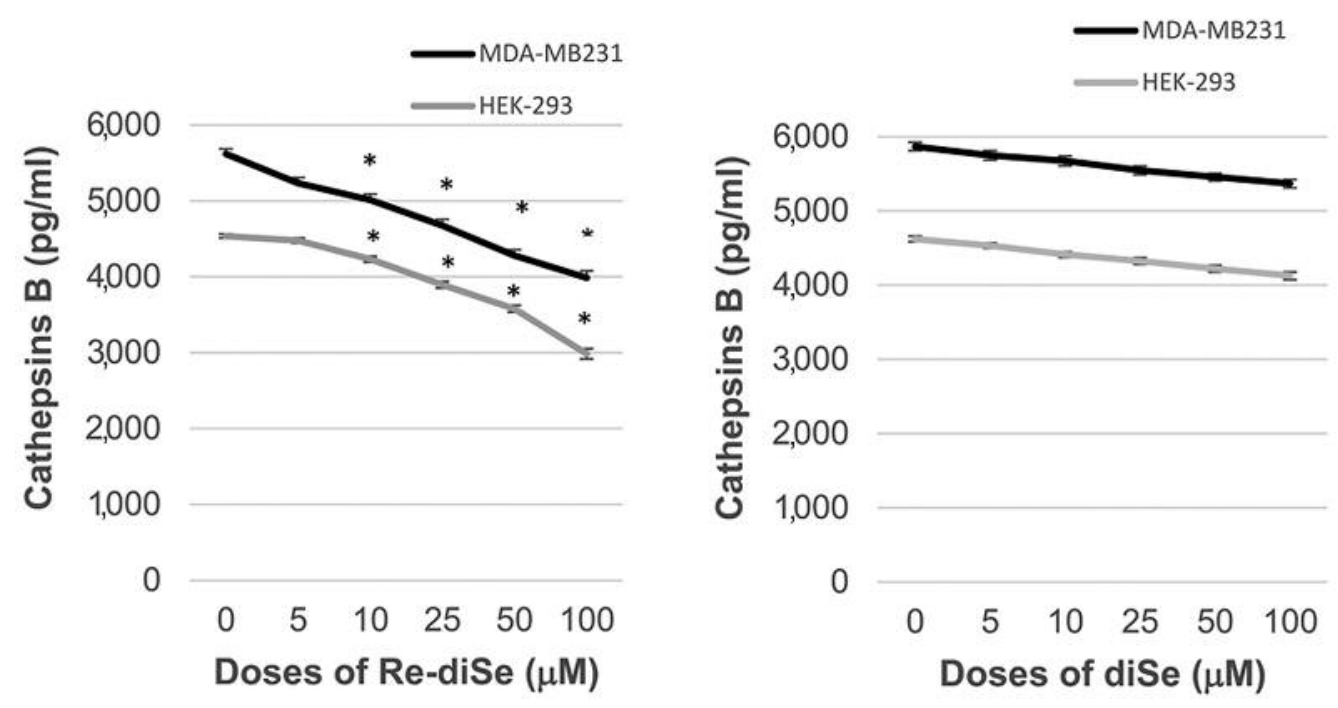

Figure 4. Dose-effects of Re-diSe and diSe on the production of cathepsin B by MDA-MB231 cancer cells and HEK293 normal cells $\left(^{*} p<0.05\right.$ versus non-treated cells).

The role of cathepsin B, which is over-expressed in a wide variety of human cancers, has been reviewed by Mijanovic et al. (1). The decreased production of cathepsins B and S may have an antitumor effect; several publications have reported that inhibition of the activity of cathepsins B and S could induce antitumor effects (11-15).

We also observed a significant decrease in cathepsin B and $\mathrm{S}$ upon Re-diSe treatment of normal HEK cells; further experiments are needed to show whether this occurs in the immune cells of the microenvironment (dendritic cells, Band T-cells, and macrophages). Cathepsin $\mathrm{S}$ is one of the major cysteine proteases. It is expressed in the lysosome of antigen presenting cells (9), with specific roles such as MHC class II antigen presentation, and cathepsin S inhibitors have been proposed as novel immunomodulators (16). However, cathepsin $\mathrm{S}$ can promote degradation of damaged or unwanted proteins in the endo-lysosomal pathway (17).

Macrophages may have opposing functions, defined as M1 (TH1-driven) and M2 (TH2-driven). These states are reversible, due to their functional plasticity, by changes in the characteristics of the microenvironment (18). Inhibition of cathepsins $B$ and $S$, using a specific inhibitor, suggest a shift from M2 to M1-like phenotype, with an increased expression of autophagy- and lysosome-associated marker genes, changes in lysosomal activity, fatty acid metabolism, synthesis of proinflammatory mediators and reduced adenosine triphosphate (ATP) levels (19). Therefore, re-polarization of tumorassociated macrophages from M2 towards an M1-like phenotype offers great potential for cancer therapy, especially for overcoming drug resistance and counteracting the immuno-suppressive effects of cancer (18).

\section{Conclusion}

The role of the Re atom has been emphasized by the significant effects of Re-diSe, but not of diSe, on cell proliferation and on the production of cathepsins. The decreased production of cathepsins B and S by Re-diSe may either have a direct action on cancer cells or indirect effects through its effects on immune cells and on the extracellular matrix. Therefore, further studies are required to investigate the effects of the Re-diSe on immune cells of the tumor microenvironment.

\section{Conflicts of Interest}

Philippe Collery is the manager of the Society for the Coordination of Therapeutic Research, and patents on rhenium compounds for pharmaceutical use belong to this Society. The other Authors declare that they have no conflict of interest related to this study.

\section{Authors' Contributions}

The idea of studying the effects of the Re compound on cathepsins was of Philippe Collery, who is involved in the development of this drug. The full protocol was elaborated by Vijay Veena. Didier Desmaele, synthesized the Re-diSe and diSe compounds. The experiments were performed by Vijay Veena in her laboratory, in collaboration with Adhikesavan Harikrishnan and Basavegowda Lakshmi. Vijay Veena and Adhikesavan Harikrishnan performed the statistical analysis. Vijay Veena and Philippe Collery were the main contributors to the writing of the manuscript.

\section{Acknowledgements}

Vijay Veena and Basavegowda Lakshmi are grateful to the Chancellor and Vice-chancellor of REVA University, Bengaluru, 
India, for their support. Adhikesavan Harikrishnan express his gratitude to the Director and Chancellor of Vinayaka Mission Research Foundation, Chennai, India.

\section{References}

1 Mijanović O, Branković A, Panin AN, Savchuk S, Timashev P, Ulasov I and Lesniak MS: Cathepsin B: A sellsword of cancer progression. Cancer Lett 449: 207-214, 2019. PMID: 30796968. DOI: 10.1016/j.canlet.2019.02.035

2 Jakoš T, Pišlar A, Jewett A and Kos J: Cysteine cathepsins in tumor-associated immune cells. Front Immunol 10: 2037, 2019. PMID: 31555270. DOI: 10.3389/fimmu.2019.02037

3 Mosi R, Baird IR, Cox J, Anastassov V, Cameron B, Skerlj RT and Fricker SP: Rhenium inhibitors of cathepsin B ( ReO(SYS)X (where $\mathrm{Y}=\mathrm{S}$, py; $\mathrm{X}=\mathrm{Cl}, \mathrm{Br}, \mathrm{SPhOMe}-\mathrm{p}$ )): Synthesis and mechanism of inhibition. J Med Chem 49(17): 5262-5272, 2006 PMID: 16913715. DOI: 10.1021/jm060357z

4 Fricker SP, Mosi RM, Cameron BR, Baird I, Zhu Y, Anastassov V, Cox J, Doyle PS, Hansell E, Lau G, Langille J, Olsen M, Qin L, Skerlj R, Wong RS, Santucci Z and McKerrow JH: Metal compounds for the treatment of parasitic diseases. J Inorg Biochem 102(10): 1839-1845, 2008. PMID: 18684510. DOI: 10.1016/j.jinorgbio.2008.05.010

5 Fricker SP: Cysteine proteases as targets for metal-based drugs. Metallomics 2(6): 366-377, 2010. PMID: 21072382. DOI: $10.1039 / \mathrm{b} 924677 \mathrm{k}$

6 Collery P, Veena V, Harikrishnan A and Desmaele D: The rhenium(I)-diselenoether anticancer drug targets ROS, TGF- $\beta 1$, VEGF-A, and IGF-1 in an in vitro experimental model of triplenegative breast cancers. Invest New Drugs 37(5): 973-983, 2019. PMID: 30632005. DOI: 10.1007/s10637-019-00727-1

7 Veena V, Harikrishnan A, Lakshmi B, Khanna S, Desmaele D and Collery P: A new model applied for evaluating a rheniumdiselenium drug: Breast cancer cells stimulated by cytokines induced from polynuclear cells by LPS. Anticancer Res 40(4): 1915-1920, 2020. PMID: 32234880. DOI: 10.21873/anticanres. 14146

8 Collery P, Mohsen A, Kermagoret A, Corre S, Bastian G, Tomas A, Wei M, Santoni F, Guerra N, Desmaële D and d'Angelo J: Antitumor activity of a rhenium (I)-diselenoether complex in experimental models of human breast cancer. Invest New Drugs 33(4): 848-860, 2015. PMID: 26108551. DOI: 10.1007/s10637015-0265-z

9 Brix K: Host cell proteases: Cathepsins. Activation of Viruses by Host Proteases : 249-276, 2020. DOI: 10.1007/978-3-31975474-1_10
10 Verma S, Dixit R and Pandey KC: Cysteine proteases: Modes of activation and future prospects as pharmacological targets. Front Pharmacol 7: 107, 2016. PMID: 27199750. DOI: 10.3389/ fphar.2016.00107

11 Rudzińska M, Parodi A, Soond SM, Vinarov AZ, Korolev DO, Morozov AO, Daglioglu C, Tutar Y and Zamyatnin AA Jr: The role of cysteine cathepsins in cancer progression and drug resistance. Int J Mol Sci 20(14): 3602, 2019. PMID: 31340550. DOI: $10.3390 / \mathrm{ijms} 20143602$

12 Pogorzelska A, Żołnowska B and Bartoszewski R: Cysteine cathepsins as a prospective target for anticancer therapies-current progress and prospects. Biochimie 151: 85-106, 2018. PMID: 29870804. DOI: 10.1016/j.biochi.2018.05.023

13 Li YY, Fang J and Ao GZ: Cathepsin B and L inhibitors: a patent review (2010 - present). Expert Opin Ther Pat 27(6): 643-656, 2017. PMID: 27998201. DOI: 10.1080/13543776.2017.1272572

14 Fuchs N, Meta M, Schuppan D, Nuhn L and Schirmeister T: Novel opportunities for cathepsin $\mathrm{S}$ inhibitors in cancer immunotherapy by nanocarrier-mediated delivery. Cells 9(9): 2021, 2020. PMID: 32887380. DOI: 10.3390/cells9092021

15 Kos J, Mitrović A and Mirković B: The current stage of cathepsin B inhibitors as potential anticancer agents. Future Med Chem 6(11): 1355-1371, 2014. PMID: 25163003. DOI: $10.4155 / \mathrm{fmc} .14 .73$

16 Thurmond RL, Sun S, Karlsson L and Edwards JP: Cathepsin S inhibitors as novel immunomodulators. Curr Opin Investig Drugs 6(5): 473-482, 2005. PMID: 15912960.

17 Wilkinson RD, Williams R, Scott CJ and Burden RE: Cathepsin S: therapeutic, diagnostic, and prognostic potential. Biol Chem 396(8): 867-882, 2015. PMID: 25872877. DOI: $10.1515 / \mathrm{hsz}-$ 2015-0114

18 Stout RD and Suttles J: Functional plasticity of macrophages: reversible adaptation to changing microenvironments. J Leukoc Biol 76(3): 509-513, 2004. PMID: 15218057. DOI: 10.1189/jlb.0504272

19 Oelschlaegel D, Weiss Sadan T, Salpeter S, Krug S, Blum G, Schmitz W, Schulze A and Michl P: Cathepsin inhibition modulates metabolism and polarization of tumor-associated macrophages. Cancers (Basel) 12(9): 2579, 2020. PMID: 32927704. DOI: $10.3390 /$ cancers 12092579
Received September 6, 2021

Revised September 21, 2021

Accepted September 22, 2021 